\title{
Katholischer Kinder- und Jugendbuchpreis 2006
}

Den Katholischen Kinder- und Jugendbuchpreis der Deutschen Bischofskonferenz 2006 erhielt der englische Autor

\section{David Almond für seine Erzählung „Feuerschlucker" (Carl Hanser Verlag, München - Wien 2005).}

Die Auszeichnung ist mit 5000 Euro dotiert. Ulli und Herbert Günther wurden für die Übersetzung mit einem Sonderpreis in Höhe von 1500 Euro ausgezeichnet. Die Preise wurden bei einem Festakt am 27. April 2006 in Münster vom damaligen Vorsitzenden der Publizistischen Kommission der Deutschen Bischofskonferenz, Weihbischof Friedrich Ostermann, verliehen.

\section{Zum Buch:}

Spätsommer 1962: Die „Kubakrise“ versetzt die Welt in Schrecken. Eine atomare Katastrophe scheint unabwendbar, die Menschen haben Angst vor einem dritten Weltkrieg. So auch die Bewohner des kleinen nordenglischen Küstenstädtchens Keely Bay. Hier wohnt der Junge Bobby Burns mit seinen Eltern. Während sich die Auseinandersetzung der Nuklearmächte zuspitzt, droht auch die kleine abgeschiedene Welt von Bobby Burns auseinander zu brechen. Er sorgt sich um seinen schwer kranken Vater. Und ihm droht der Verweis von der Schule, weil er sich gegen die brutale Willkür der Lehrer wehrt. Inmitten dieser Eskalation begegnet Bobby dem geheimnisvollen Feuerschlucker und Entfesselungskünstler Mr. McNulty. Es entsteht eine ungewöhnliche Beziehung zwischen dem alten verwirrten Mann und dem Jungen.

David Almond erzählt in prägnanten und kurzen Sätzen. Er fasst die Welt und das Denken der Menschen, ihre Sorgen und Träume in poetisch dichte Bilder. „Feuerschlucker“ ist ein wunderbares Buch über das Erwachsenwerden, über das Miteinander ganz unterschiedlicher Menschen, die zueinander finden, wenn sie offen füreinander sind. Es ist auch ein Plädoyer für Solidarität, Würde und Achtung vor dem Leben.

\section{Zu den Preisträgern:}

David Almond, geboren 1951 in Felling-on-Tyne in der Nähe von Newcastle, lebt als freier Schriftsteller in Großbritannien. Zuvor war er als Lektor und Lehrer tätig. Almond schreibt Romane sowohl für Erwachsene als auch für Kinder und Jugendliche. Für seine literarischen Leistun- 
gen wurde er bereits mit dem Whitbread Children's Book Award 1998 und der Carnegie Medal 1998 ausgezeichnet. Der Autor ist verheiratet und Vater einer Tochter.

Herbert Günther, geboren 1947 in Göttingen, arbeitete als Buchhändler und Lektor. Seit 1988 ist er als freier Schriftsteller und Übersetzer tätig. Er hat zahlreiche Kinder- und Jugendbücher sowie Drehbücher für das Fernsehen geschrieben und wurde $\mathfrak{u}$. a. mit dem Friedrich-BödeckerPreis ausgezeichnet. Gemeinsam mit seiner Frau Ulli Günther, geboren 1949 in Wurzen bei Grimma, hat er über 70 Kinder- und Jugendbücher vom Englischen ins Deutsche übersetzt. Ulli Günther ist als Buchhändlerin tätig. Das Ehepaar Günther lebt mit seinem Sohn in Friedland bei Göttingen. 